\title{
Selenium speciation and reactivity in a coastal range watershed: from mountain lakes to estuarine waters
}

DAVID AMOUROUX ${ }^{1}$, ANDREA ROMERO-RAMA ${ }^{2}$, EMMANUEL TESSIER $^{3}$ AND MAITE BUENO ${ }^{2}$

${ }^{1}$ CNRS, Université de Pau et Pays de l'Adour, E2S UPPA, IPREM

${ }^{2}$ Université de Pau et des Pays de l'Adour, E2S UPPA, CNRS, IPREM, Institut des Sciences Analytiques et de Physico-chimie pour l'Environnement et les matériaux

${ }^{3}$ Université de Pau et des Pays de l'Adour, E2S UPPA, CNRS, IPREM

Presenting Author: david.amouroux@univ-pau.fr

To better constrain how Se aquatic biogeochemistry evolves from mountain headwaters to downstream end-member, investigations were conducted in alpine lakes (Western Pyrenees) and in the Adour river and estuary (Bay of Biscay). In lakes, biannual sampling (2017-18) was carried out after snowmelt (June/July) and in early fall (October), while in the Adour river and estuary, seasonal sampling of water was performed in May and September 2017 and January 2018. In all water samples total bulk and dissolved Se (TDSe) were determined together with dissolved Se oxyanions such as selenite (Se(IV)) and selenate $(\mathrm{Se}(\mathrm{VI}))$ [1]. Reduced Se fraction ( $\mathrm{Se}(0), \mathrm{Se}(-\mathrm{II})$-organic $\mathrm{Se})$ was obtained by difference to TDSe. Volatile Se species (TVSe) such as DMSe, DMSSe and DMDSe were also determined [1].

In upstream lake waters, concentrations of TDSe ranged from $7 \pm 1$ to $80 \pm 9 \mathrm{ng} \mathrm{Se} \mathrm{L}^{-1}$, being selenate ubiquitously observed in most cases (8-128\% of TDSe). Selenite was in the range between $<$ LoQ to $4 \pm 1 \mathrm{ng} \mathrm{Se} \mathrm{L}^{-1}$, and a fraction was in the form of reduced Se. TVSe was ranging from $3 \pm 4$ to $120 \pm 20 \mathrm{pg} \mathrm{Se} \mathrm{L}^{-1}$. Selenate was the major Se compound in water and represented in average $63 \%$ of total dissolved Se that was correlated with sulfate concentrations. These results show that Se in alpine lakes originates both from local geogenic sources and atmospheric wet depositions.

In river and estuarine waters, concentration range for TDSe varied from 71 to $771 \mathrm{ng} \mathrm{Se} \mathrm{L}^{-1}$. Se(VI) was the main species (50\% of TDSe in average); while Se(IV) and reduced Se fraction represented, in average, $11 \%$ and $42 \%$ of TDSe. TVSe ranged from 51 to $2757 \mathrm{pg} \mathrm{Se} \mathrm{L}^{-1}$. The results exhibit an increase of total $\mathrm{Se}$ in the river waters entering the estuary compared to total Se concentrations in headwaters. The influence of agricultural land use on Se inputs was demonstrated with a clear relationship with nitrate concentrations. Downstream in the estuary, selenium fate was dramatically modified during warmer productive periods through significant uptake and transformation to reduced and volatile compounds.

REFERENCES

[1] Lanceleur et al., Biogeochem. 2019. 145: 193-211. 